\title{
Refill Friction Stir Spot Welding of Similar and Dissimilar Alloys: A Review
}

\author{
Xiao-Song Feng ${ }^{1} \cdot$ Song-Bin $\mathrm{Li}^{1} \cdot \mathrm{Li}-\mathrm{Na} \mathrm{Tang}^{1} \cdot$ Hui-Min Wang ${ }^{2}$
}

Received: 11 April 2019 / Revised: 21 September 2019 / Published online: 19 December 2019

(C) The Chinese Society for Metals (CSM) and Springer-Verlag GmbH Germany, part of Springer Nature 2019

\begin{abstract}
Refill friction stir spot welding, also known as friction spot welding (FSpW), is a solid-state welding process suitable for spot joining of lightweight materials. Through the efforts of improving joint quality for similar and dissimilar materials, for example, aluminum and magnesium, this joining technology is well developed. The joining mechanism and process characteristics of FSpW have been widely studied. However, the application of FSpW in industry has not been entirely successful. In this review article, the research of similar and dissimilar material joints, such as, $\mathrm{Al} / \mathrm{Cu}, \mathrm{Al} / \mathrm{Ti}, \mathrm{Al} / \mathrm{Mg}$ and $\mathrm{Al} /$ Steel, is summarized. The microstructural features and mechanical properties of the joints, welding tool and the application development are discussed in detail.
\end{abstract}

Keywords Refill friction stir spot welding $\cdot$ Dissimilar joints $\cdot$ Microstructure $\cdot$ Mechanical properties $\cdot$ Welding parameters

\section{Introduction}

Refill friction stir spot welding (refill FSSW) was developed and patented by Helmholtz-Zentrum Geesthacht (formerly GKSS) in 1996 [1] (U.S. Patent 6,722,556 B2). The process was also known as friction spot welding (FSpW). It is considered as one of the most attractive solid-state spot welding processes for producing high-quality spot weld, refilling the weld keyhole of friction stir welding (FSW) and removing welding defects [2-4].

As shown in Fig. 1, two or more materials in overlap configuration can be joined with FSpW. The rotational tool consists of three independently controlled parts: a sleeve, a pin and a clamping ring. By rotating the pin and the sleeve in opposite direction, the solid-state metallurgical bond is generated between sheets due to the frictional heat and mechanical material mixture. A FSpW-produced joint often has a visually flat surface while a keyhole is left with conventional

Available online at http://link.springer.com/journal/40195.

Xiao-Song Feng

fxsupc@163.com

1 Shanghai Aerospace Equipments Manufacturer Co., Ltd, Shanghai 200245, China

2 National Center for Materials Service Safety, University of Science and Technology, Beijing, Beijing 100083, China
FSSW on the surface [5]. Figure 1d shows the flat surface of the spot weld after the rotational tool is withdrawn $[6,7]$.

Due to excellent mechanical properties of the spot welds, low joining temperature and keyhole-free surface, FSpW is a promising joining method for lightweight materials with low melting point, such as $\mathrm{Al}$ and $\mathrm{Mg}$ alloys, especially for dissimilar welds of $\mathrm{Al} / \mathrm{Mg}, \mathrm{Al} / \mathrm{Cu}, \mathrm{Al} / \mathrm{Ti}$ and $\mathrm{Al} / \mathrm{Steel}$. In the past decades, many aspects of FSpW have been academically studied. The present review mainly focuses on welding parameters and their effects on joint microstructure and mechanical properties, the welding tool and application development.

\section{Microstructure of FSpW Joints}

\subsection{Microstructure of Similar Alloy Joints}

\subsubsection{Typical Cross-Sectional Microstructure of Joints}

Figure 2 shows the microstructure in cross section of 2024 aluminum alloy joint, which is similar to that of 6061 and AlMgSc aluminum alloys and AZ31 magnesium alloy. Based on grain structure, the welded area is characterized as two zones: stir zone (SZ) and thermomechanically affected zone (TMAZ), which is similar to FSW welded area [7-10]. The TMAZ is often characterized by grains 


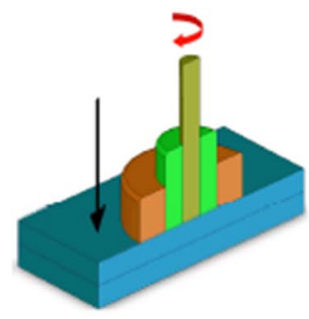

a

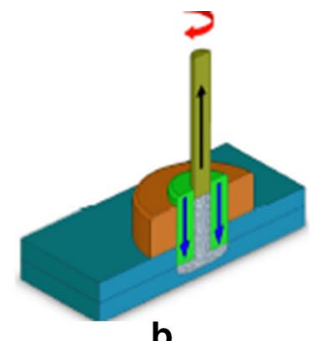

b
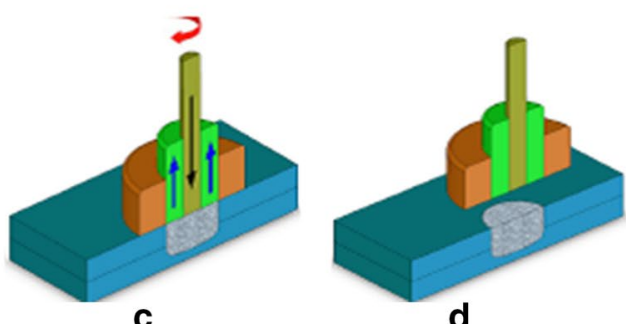

d

Fig. 1 Schematic illustration of refill friction stir spot welding stages [7]

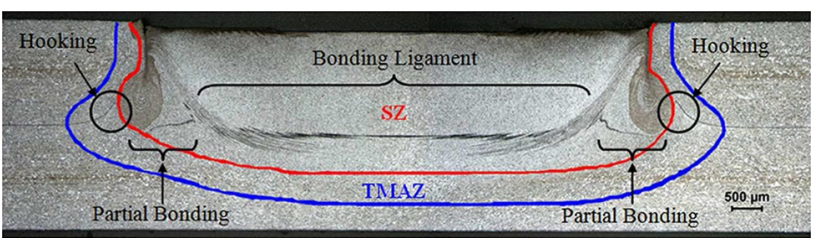

Fig. 2 Cross section of a typical joint [7]

with a $90^{\circ}$ rotation from the base material (BM) grains due to the tool stirring. The $\mathrm{SZ}$ is the region in the center of the spot with fine dynamically recrystallized grains. Partially recrystallized grains are often found in the center of the SZ due to the relatively low local shear strain. The bottom border of the $\mathrm{SZ}$ is characterized by fibrous structures and textural structures $[10,11]$.

Other geometric features of the joint microstructure, such as bonding ligament, partial bonding and hooking, are often observed in the joint of $\mathrm{Al}$ and $\mathrm{Mg}$ alloys. Bonding ligament is a region where strong bonding between the upper and lower sheets is expected. But for $\mathrm{Mg}$ alloy joints, voids or cavities are often produced in bonding ligament (or bonding line) [12]. Partial bonding is the transition area between completely separated sheets and bonding ligament [7]. However, bonding ligament and partial bonding are not always generated in the joints. Some researchers found that a well-defined bonding ligament was not presented and the joint showed a typical microstructure of Al alloy friction spot connection [11]. The disappearance of bonding ligament is possibly attributed to better material mixing, which is improved by adequate processing temperatures and shear deformation rates. Hooking is characterized as a geometrical flaw. It is produced by upward bending of the sheet interface during the sleeve penetration and retraction and is defined as oxide layer that is not completely destroyed. A typical geometric feature of hooking takes a "V" shape, displaying a sharpened edge pointing to the upper surface. For deeper plunge depth (PD), a higher vertical hooking was observed. Santana et al. [8] also reported that the hooking height significantly affects the mechanical performance of the joint.

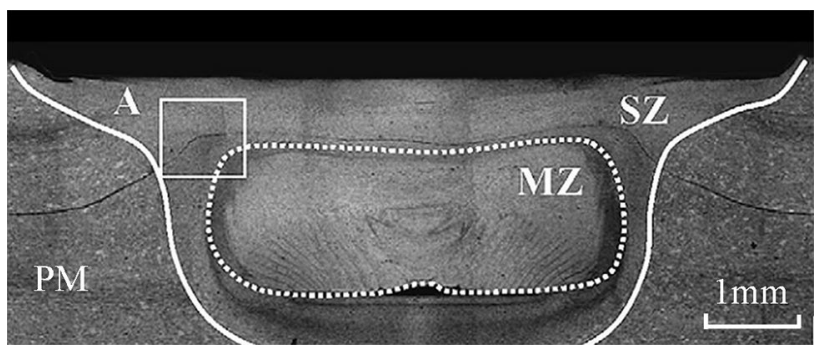

Fig. 3 Macroscopic appearance of a FSpW joint with refilled probe hole [16]

The zone between the SZ and the TMAZ, characterized by fine grains and shear texture, was also investigated by some researchers $[4,13,14]$. This zone remains similar grains in size and shape as in the SZ. For the weld of 2198T6, Castro et al. [14] found that the microstructure features of this zone was a result of the material extrusion, caused by the pin, into the stir zone in contact with sleeve outer surface. The extrusion resulted in smaller grains in this zone. Similar features and phenomenon were also reported by Reimman et al. [4] in a study of keyhole repairs of AA2198 using FSpW. For $6061 \mathrm{Al}$ alloy, at the sleeve periphery, the shear texture formation was associated with the material flow when material was discharged from the bottom of the thread on the rotating sleeve [15].

Another type of FSpW is performed using a specially designed double-acting tool. The tool consists of outer flat shoulder and inner retractable probe. This process is different from the typical FSpW process invented by HZG [16]. Therefore, the weld microstructure is different from the typical FSpW weld. The spot weld was classified into two zones: mixed zone (MZ) and stir zone (SZ) (Fig. 3).

\subsubsection{Local Melting in the Process}

During FSpW process, the process temperature up to 0.99 $\mathrm{TM}$ (temperature of melting point) and melting phenomenon have been reported [17]. For the welding process of $\mathrm{Al}-\mathrm{Zn}-\mathrm{Mg}-\mathrm{Cu}$ alloy, the peak temperature was higher than 
the incipient melting temperature. As shown in Fig. 4b, a " $U$ " line formed in the SZ due to the local melting along the grain boundaries. During FSpW, the liquid phase was first formed and gathered in the sleeve cavity. After that, it was driven by the flowing plastic material to redistribute as a "U-shaped" line in the SZ. Owing to the inharmonious plastic deformation on the two sides of the "U-shaped" line, the liquid phase was partially torn to form liquation cracks. With cooling, the rest of the liquid phase transforms into

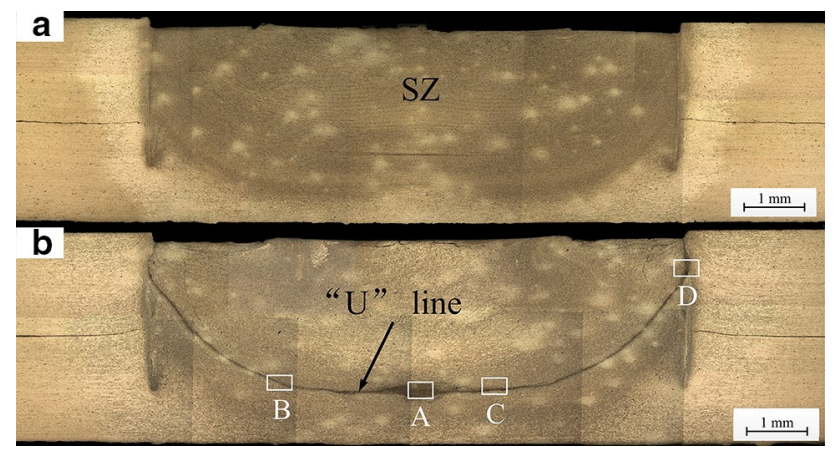

Fig. 4 Cross sections of FSpW joints welded at tool rotation speeds of a 1250, b $2500 \mathrm{rpm}$ ("U" line with local melting) [17] eutectic films. Therefore, both eutectic films and liquation cracks were found along the " $U$ " line [17].

For AZ31 magnesium alloy, the local melting phenomenon was also reported. According to the thermal cycle measurement, a maximum temperature of $514{ }^{\circ} \mathrm{C}$ was achieved in the SZ during the dwell time period, which is $85 \%$ of the alloy solidus temperature of $605^{\circ} \mathrm{C}$ [12]. Although the process was proved to happen in the solid state, the formation of cavities even under a compressive load (exerted by the tool motion) must be related to a localized incipient melting resulting from excessive heating in the vicinity of the rotational tool (Fig. 5).

\subsection{Microstructure of Dissimilar Alloy Joints}

Due to its solid-state characteristics, FSpW has become an excellent alternative to produce dissimilar joints in a fast and reliable way. The typical dissimilar material configurations include $\mathrm{Al} / \mathrm{Mg}, \mathrm{Al} / \mathrm{Cu}, \mathrm{Al} / \mathrm{Ti}$ and $\mathrm{Al} /$ Steel.

\subsubsection{Al/Mg Dissimilar Alloy Weld}

Suhuddin et al. [13, 18, 19] reported the microstructure characteristics of dissimilar 5754/AZ31 welds produced by FSpW. In their research, the welding cycle stopped during
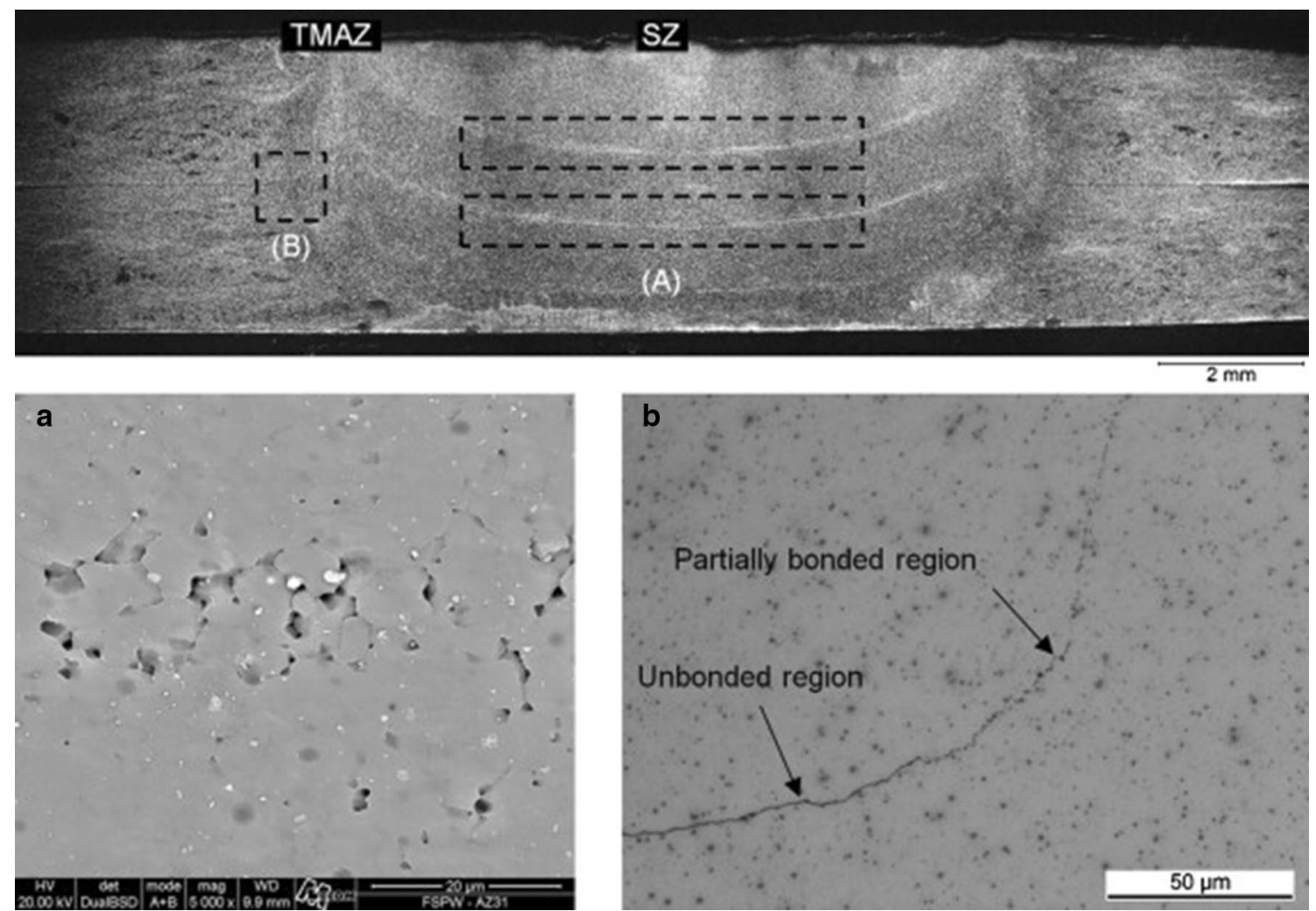

Fig. 5 Cross section microstructure of an AZ31 friction spot joint: a cavities resulting from local melting; b hooking region [12] 
the dwell period with emergency button. The "as-quenched sample" was prepared by a solution of ice and water to freeze the microstructure. It represented different stages of the process. The observation of eutectic phases indicated the formation of liquid phase during the process (Fig. 6). Due to the rapid atomic diffusion in liquid phase, the intermetallic compounds of $\mathrm{Al}_{12} \mathrm{Mg}_{17}$ and $\mathrm{Al}_{3} \mathrm{Mg}_{2}$ were primarily developed. No liquation cracks were observed in the as-welded joint [20]. The results of Dong et al. [21] showed that, for 5083/AZ31 welds, little liquid eutectic phase was formed at $1 \mathrm{~s}$.

\subsubsection{Al/Cu Dissimilar Alloy Weld}

In $\mathrm{FSpW} \mathrm{Al} / \mathrm{Cu}$ weld, the observed eutectic liquation mainly included $\mathrm{Al}-\mathrm{MgCuAl}_{2}$ eutectic structures and divorced $\mathrm{MgCuAl}_{2}$ eutectic structures. Along the interface, a $\mathrm{CuAl}_{2}-\mathrm{Al}_{4} \mathrm{Cu}_{9}$ composite layer of varied thickness was also formed [22], while the process parameters did not evidently alter the intermetallic composite layer as well as its thickness [23]. At a mild condition, the $\mathrm{Al} / \mathrm{Cu}$ joint interface showed flat features (Fig. 7a), surrounded by fine particles (Fig. 7b, c) of $\mathrm{MgCuAl}_{2}$ and $\mathrm{Al}_{6}(\mathrm{Mn}, \mathrm{Fe})$ based on the results of EDS and EBSD. The interface thickness was less than 0.2-0.3 $\mu \mathrm{m}$ under the sleeve (Fig. $7 \mathrm{~b}$ ) and $0.5-1.2 \mu \mathrm{m}$ at the center (Fig. 7c). At a harsh condition, the $\mathrm{Al} / \mathrm{Cu}$ interface showed more deformed features (Fig. 7d). Local eutectic liquefaction (Al- $\mathrm{MgCuAl}_{2}$ eutectic) was found at the regions of the dark contrast, which would be the product of local eutectic liquefaction ( $\mathrm{Al}-\mathrm{MgCuAl}_{2}$ eutectic) that is associated with the mass transport induced by material flow and severe plastic deformation. However, the interface consisted of the same composite layer, which is slightly thicker (Fig. 7e, f) [23].

\subsubsection{Al/Ti Dissimilar Alloy Weld}

The formation of intermetallic compounds at the interface during the welding process was analyzed [24-27]. Plaine et al. [24] observed that the joint interface was mainly a continuous layer, consisting of large elongated grains and small fine grains of $\mathrm{TiAl}_{3}$ intermetallic compounds. The interface thickness was significantly influenced by the dwell time. In addition, $\mathrm{Al} / \mathrm{Fe} \mathrm{IMC}$ (intermetallic compounds) was also presented in the reaction layer near the $\mathrm{TiAl}_{3} / \mathrm{Ti}$ interface. They also demonstrated that some Si element was dissolved in the $\mathrm{TiAl}_{3}$ layer (approximately 10\%) [25] and a typical dendritic structure was formed under the highest rotation speed, which resulted in a complex and cracked interfacial reaction layers near the Ti/Al interface. Figure 8 shows the microstructure of the $\mathrm{Ti} / \mathrm{Al}$ interface with a rotation rate of $3000 \mathrm{rpm}$. Complex and cracked interfacial reaction layers were formed near the Ti/Al interface. The observation of dendritic structure indicated the material melting. The average width of the interfacial reaction layers was approximately $2 \mu \mathrm{m}$ [25].

The growth kinetics of intermetallic compound was also investigated, and the results showed that an incubation time of approximately $2.7 \mathrm{~s}$ was necessary before it nucleated at the $\mathrm{Ti} / \mathrm{Al}$ interface and grew laterally to form a continuous layer. Afterward, the $\mathrm{TiAl}_{3}$ layer grew toward the $\mathrm{Al}$ side with a corresponding growth rate [26].

\subsubsection{Al/Steel Dissimilar Alloy Weld}

For FSpW welds of $\mathrm{Al}$ alloy to $\mathrm{Zn}$-coated steel, a solid-liquid structure was produced, which was possibly induced by $\mathrm{Zn}$ melting and the dissolution of $\mathrm{Mg}-\mathrm{Al}$ into $\mathrm{Zn}$ liquid [28].

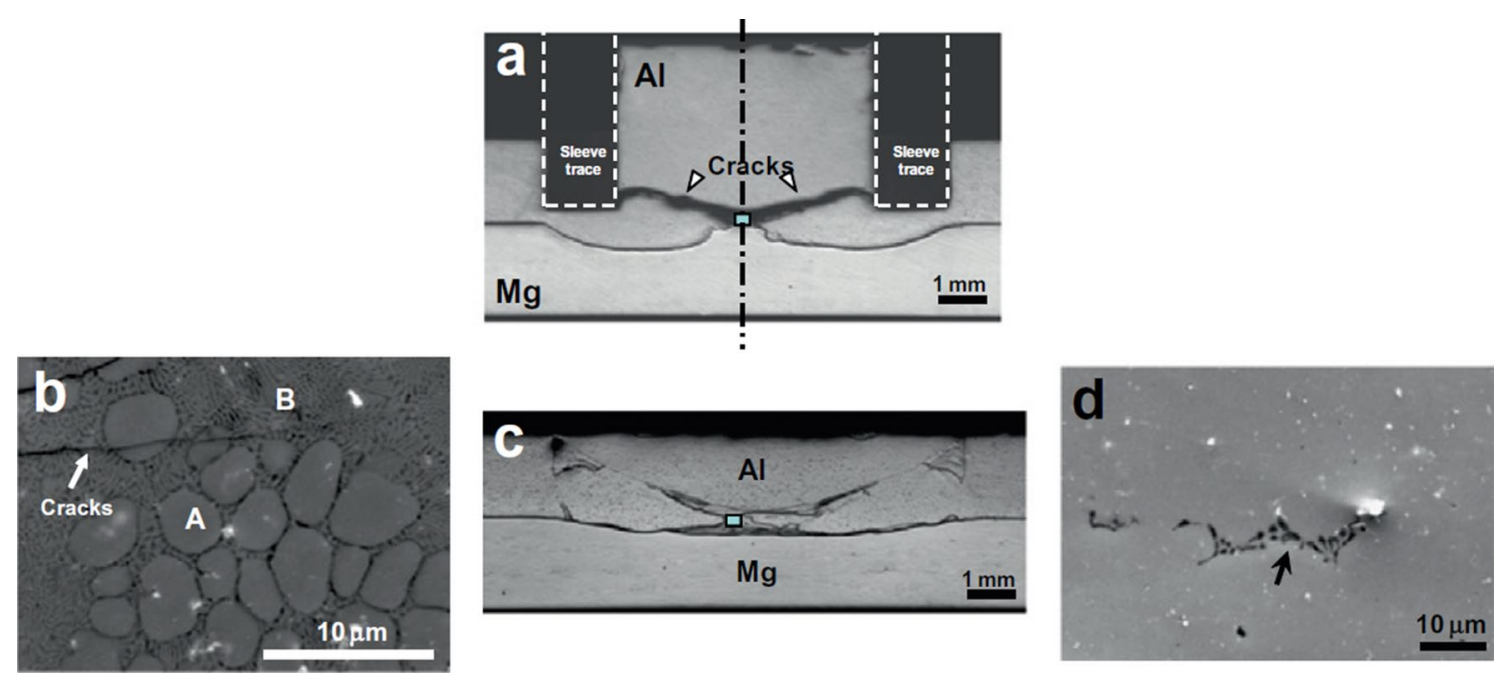

Fig. 6 Quenched sample a and the welded sample c; and a micrograph taken from the weld center, as marked in a and $\mathbf{c}$, for $\mathbf{b}$ and $\mathbf{d}$, respectively [13] 

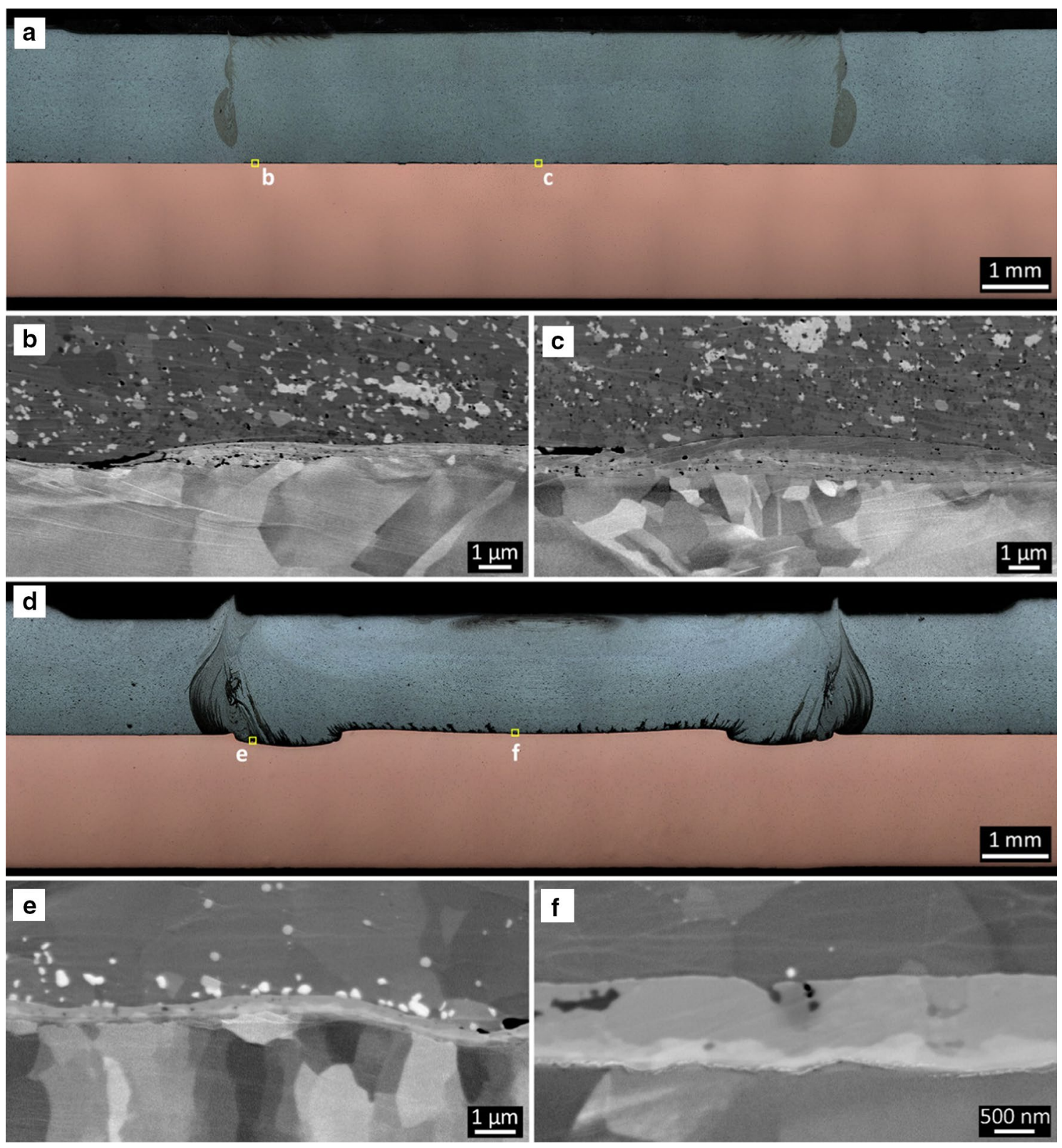

Fig. 7 Representative macro- and microstructure of Al/Cu joints: a overview of the joint with rotation speed of $1200 \mathrm{rpm}$, plunge depth of $1.6 \mathrm{~mm}, \mathbf{b}$ and $\mathbf{c}$ magnified views of locations b, c; $\mathbf{d}$ overview of the joint with rotation speed of $2000 \mathrm{rpm}$, plunge depth of $2 \mathrm{~mm}, \mathbf{e}$ and $\mathbf{f}$ magnified views of locations e, $\mathrm{f}[23]$

Shen et al. [29] fabricated FSpW welds of Al/Zn-coated steel and $\mathrm{Al} / \mathrm{AlSi}$-coated steel welds. Their results showed that $\mathrm{Al}-\mathrm{Zn}$ eutectic layers with varied thickness were formed at the joint interface. Other than that, the nanoscale intermetallic (IMC) was discontinuous, which was attributed to a liquid/solid reaction mechanism. In the joint of $\mathrm{Al} / \mathrm{AlSi}$ coated steel, solid-state metallurgical bonding occurred at the joint interface.

Figure 9 shows the microstructure of dissimilar welds for $\mathrm{Al}-\mathrm{Mg}-\mathrm{Mn}$ alloy and $\mathrm{Zn}$-coated high-strength lowalloy steel. A solid-liquid structure of Al solid solution in
$\mathrm{Mg}-\mathrm{Al}$-rich $\mathrm{Zn}$ liquid was formed. Exposure of steel surface to $\mathrm{Mg}-\mathrm{Al}$-rich $\mathrm{Zn}$ liquid led to the formation of $\mathrm{Fe}_{2} \mathrm{Al}_{5}$ and $\mathrm{Fe}_{4} \mathrm{Al}_{13}$ intermetallics (Fig. 9e) [30].

In the research of Dong et al. [31], Zn- and O-rich layer was generated at the $\mathrm{Al}$ side of the joint interface. $\mathrm{ZnO}$ phase was detected on the fractured surface of both $\mathrm{Al}$ and steel sides. In the cross section of the joint (Fig. 10), it was recognized that the formation of two $\mathrm{Zn}$-rich zones was contributed to the zinc melting or dissolution in thermoplastic aluminum alloy. Therefore, the solid solution formed by the thermomechanically stirring action. 

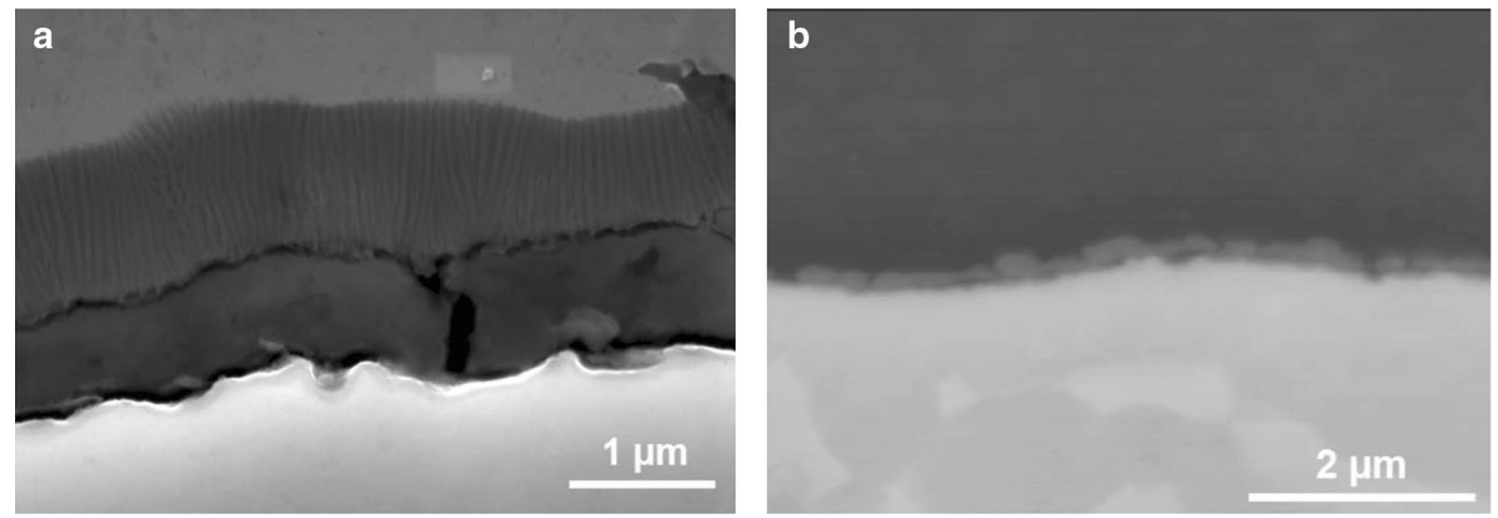

Fig. 8 SEM micrographs of joint interface produced with a tool RS of $3000 \mathrm{rpm}$ a under the pin (weld center); b under the sleeve [25]

\section{Mechanical Properties of the Joints}

\subsection{Microhardness of the Joints}

Microhardness across the FSpW joint section presented high values in the SZ and low values in the HAZ and the TMAZ [5, 6]. In Fig. 11, the average hardness of the BM is about $80 \mathrm{HV} 0.5$. It starts to decrease in the HAZ to a minimum of 70 HVO.5 at the interface between the HAZ and TMAZ. The hardness loss at the outer limits of the HAZ is associated with the recovery of the as-rolled BM microstructure due to the temperature increase during welding process. In the SZ, the intense plastic deformation and high temperatures cause the microstructure to undergo dynamic recrystallization. And the high temperature would lead to the solubilization of the precipitates and their re-precipitation during cooling right after welding. The microhardness change in the SZ was probably associated with the two mechanisms taking place together: reduction of grain size and reprecipitation accompanied by aging. Pieta et al. [32] found that welds with low-microhardness fluctuations across the section had good mechanical performance.

For Al/Ti dissimilar joints, the comparable hardness values to the BM were obtained in the SZ, which was attributed to the breakdown and homogenization of precipitates [26]. Additionally, it indicated that the average hardness in the $\mathrm{Al}$ side decreased by approximately $25 \%$ in the HAZ, while at the Ti side there is no obvious change due to the insufficient process temperature [33].

\subsection{Tensile Shear Strength of the Joints}

Table 1 summarizes the maximum tensile shear strength and the typical fracture modes of FSpW joints. It clearly indicated that the joint tensile shear strength for $\mathrm{Al}$ alloys is up to the maximum $14.73 \mathrm{kN}$ with a 9-mm sleeve diameter, which is much higher than that of the resistance spot welding. The dissimilar alloy joints also showed an excellent tensile shear strength, which is maximum $3.75 \mathrm{kN}$ for $\mathrm{Al} /$ $\mathrm{Mg}, 7.1 \mathrm{kN}$ for $\mathrm{Al} / \mathrm{Cu}$ joint, $7.4 \mathrm{kN}$ for $\mathrm{Al} / \mathrm{Ti}$ and $7.8 \mathrm{kN}$ for $\mathrm{Al} /$ steel. However, it needs to be mentioned that some of the experimental results showed an extremely high data scattering. For example, for dissimilar $\mathrm{Al} / \mathrm{Mg}$ joint, the standard deviation of joint shear force is over than $10 \%$, which is possibly related to the area with fracture surface and the distribution of IMCs, particularly in the interfacial area [19].

\subsubsection{Similar Alloys Joints}

The effects of process parameters, such as plunge depth, rotation speed and plunge time, were widely investigated to obtain high lap shear force. Investigations on the microstructural characterization revealed that hooking and welded area played fundamental roles in the mechanical performance. The process parameters had a significant influence on the shape and dimensions of hooking and/or partial bonding line. The analysis on the effect of individual process parameter showed that the plunge depth was the primary factor to create high lap shear force in similar $\mathrm{Al}$ joint $[35,40]$. When the plunge depth was restricted to the upper sheet, the hooking feature was not found to be significant to affect the joint static shear strength [8]. The results of $7075 \mathrm{Al}$ joints showed that significantly better weld properties were obtained by increasing the dwell time [39].

\subsubsection{Dissimilar Alloys Joints}

For welding process of dissimilar alloys, it is found that plunge depth was a more significant parameter for the joint strength, especially for the joint with high-melting-point bottom plate. With the plunge depth, the bottom sheet could deform into a concave shape to form a mechanical interlocking. In $\mathrm{Al} / \mathrm{Cu}$ welding process, only the influence of the plunge depth and the interaction 

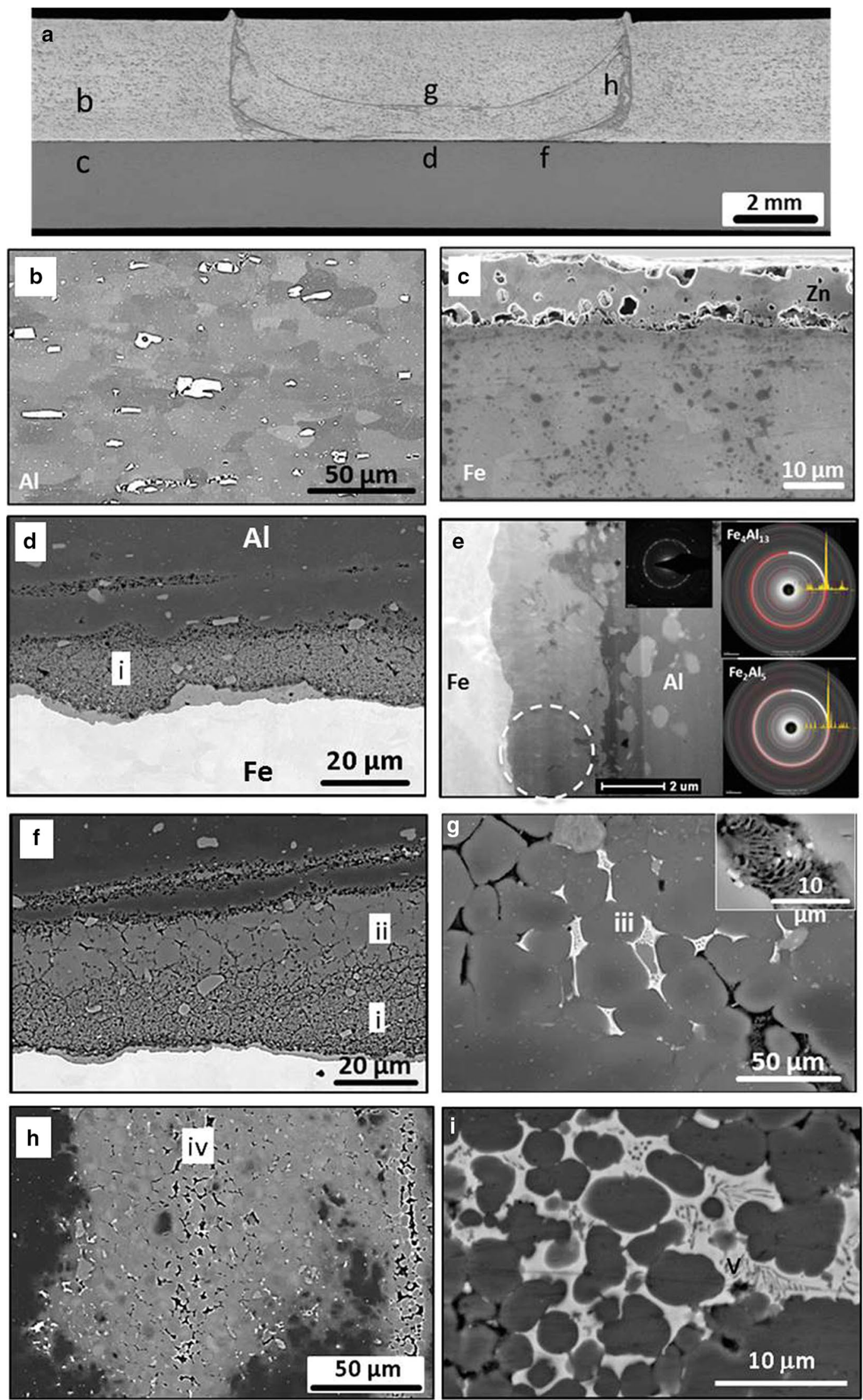

Fig. 9 Microstructure of a weld produced by FSpW. Cross-section image $\mathbf{a}$, base materials $\mathbf{b}$, $\mathbf{c}$; higher-magnification images of selected areas $\mathbf{d}-\mathbf{i}$ [30] 


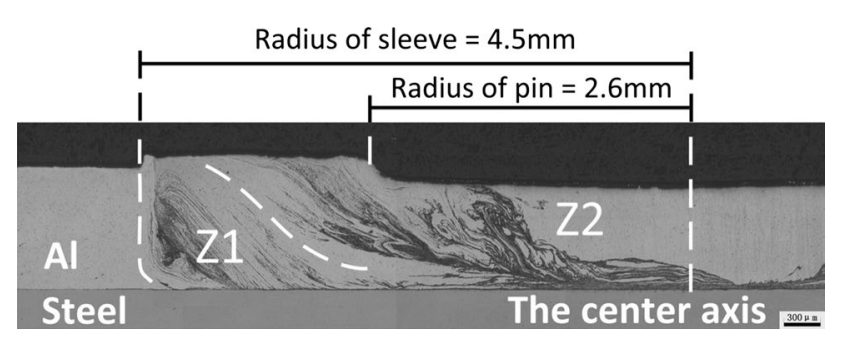

Fig. 10 Joint cross-sectional view of aluminum alloy to galvanized steel sheets [31]

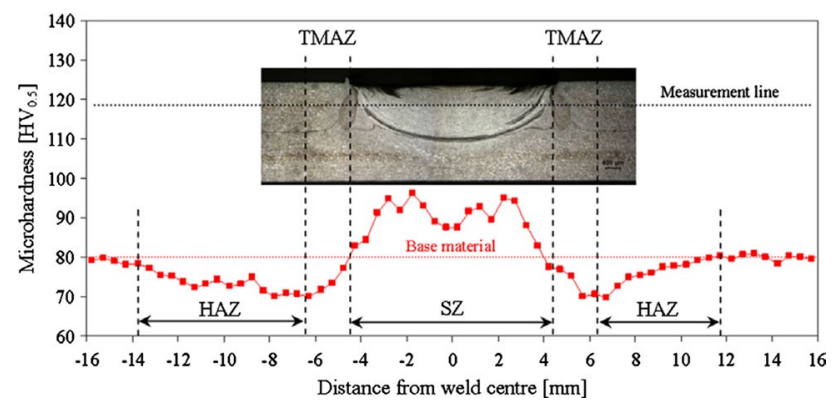

Fig. 11 Typical microhardness profile measured in the mid-thickness of the upper sheet of FSpW joint [5]

between rotation rate and plunge depth were considered since the rotation rate and dwell time are insignificant to the joint tensile shear strength [23]. The results showed that large plunge depth can lead to an interlock, which restrains the crack propagation and changes the fracture mode. Furthermore, the mechanical interlocking is possibly compromised at a high rotational speed because of the formed tunnel defects at the $\mathrm{Al} / \mathrm{Cu}$ interface.

Besides the plunge depth, the welding temperature is another important factor to the joint mechanical strength. It is determined significantly by rotation rate and dwell time. The joint strength of AA6181-T4 and Ti6Al4V indicated that the tool rotation rate has the largest influence on the joint shear resistance, followed by its interaction with dwell time [28]. The similar results were also obtained in Al/Steel lap configuration welding. When a high rotation rate was applied on a thick defective $\mathrm{Zn}$-rich $\mathrm{Al}$ layer and $\mathrm{Fe}-\mathrm{Al} \mathrm{IMC}$ were produced at the faying surface [30]. Many studies on Al/Ti FSpW joints illustrated that the rotation rate had significantly influence on weld tensile shear strength, and followed by the interaction of rotation rate and plunge depth [28]. However, in the results of other researchers, the lap shear strength of $\mathrm{Al} /$ Ti joint mainly depended on dwell time that determined the thickness of interface layer [13].

\subsubsection{Joint Fracture Modes}

The tensile shear strength of joint is also related to the fracture behaviors under shear loading. The typical fracture modes are through-the-weld and pull-out. For the pull-out mode, different types, such as pull-out with tearing (noncircumferential pull-out) and pull-out with plug (circumferential pull-out), are summarized by Leonardo et al. [12]. For dissimilar Al-based and high-melting-point alloy joints, such as $\mathrm{Al} / \mathrm{Cu}, \mathrm{Al} / \mathrm{Ti}$ and $\mathrm{Al} /$ steel, the fracture mode of "at the interface" was usually observed.

\subsection{Fatigue Properties of the Joints}

\subsubsection{Fatigue Performance of Similar Alloy Joints}

There were only few investigations of fatigue properties conducted on the FSpW joint. The current research results show that fatigue life of the FSpW welds was better than those with the conventional FSSW. The interfacial hooking had a significant influence on the joint fatigue performance for defect-free joints. Moreover, the joint defects also led to a significant reduction in fatigue life [42]. It was found that in all fatigue tests, the fatigue crack initiated at the hooking tip or the tips of the unwelded joint interface for defectfree joint. Therefore, the hooking was considered a stress intensity factor (SIF) and acted as the crack origin [6]. The downward interfacial hooking was found to represent better fatigue life, offering infinite fatigue life at $15 \%$ of the maximum strength load for 2024-T3, while the upward hooking profile had lower fatigue life and higher scatter under similar stress amplitude [43]. With the restriction of the tool penetration into only the upper sheet, the hooking was minimized. And unstable fatigue crack growth did not take place [9].

The investigation of fatigue behavior of 7075-T76 Al showed that the crack propagated circumferentially around the weld nugget with lower loads in fatigue tests, while around the SZ with high loads [27]. The results of 6061$\mathrm{T} 6 \mathrm{Al}$ joint showed that there were three different modes of fatigue fracture [44]. Under low cycle loading conditions, the pull-out fracture of weld nugget was observed. Under high cycle conditions with higher load ranges, the pull-out and circumferential fracture of the weld nugget was observed, whereas under high cycle with lower load ranges, the fracture of the BM was observed.

\subsubsection{Fatigue Performance of Dissimilar Alloy Joints}

For dissimilar joints, better fatigue performance was obtained in FSpW Al/Ti joints [33] and $\mathrm{Mg} /$ steel joints [45] than in $\mathrm{Al}$ or $\mathrm{Mg}$ similar joints. The better performance of the dissimilar joints was attributed to two aspects: the absence of the typical 
Table 1 Tensile shear strength and type of fracture

\begin{tabular}{|c|c|c|c|c|}
\hline Materials (top/bottom plate) & $\begin{array}{l}\text { Top/bottom plate thick- } \\
\text { ness }(\mathrm{mm})\end{array}$ & Tensile shear strength & Type of fracture & References \\
\hline 2198-T8/2198-T8 & $3.2 / 3.2$ & $14.73 \mathrm{kN}$ & Through-the-weld & {$[14,32]$} \\
\hline 2024-T3/2024-T3 & - & $10.3 \mathrm{kN}$ & - & [11] \\
\hline 2A14-T4/2A14-T4 & $2.0 / 2.0$ & $10.03 \mathrm{kN}$ & Shear-plug fracture & [34] \\
\hline $5042-\mathrm{O} / 5042-\mathrm{O}$ & $1.5 / 1.5$ & $6.21 \mathrm{kN}$ & "Pull out" fracture & {$[35]$} \\
\hline $5083-\mathrm{O} / 5083-\mathrm{O}$ & $2.0 / 2.0$ & $7.72 \mathrm{kN}$ & Plug fracture & [36] \\
\hline 6181-T4/6081-T4 & $1.7 / 1.7$ & $7 \mathrm{kN}$ & - & {$[5]$} \\
\hline 6061-T6/6061-T6 & $2.0 / 2.0$ & $9.76 \mathrm{kN}$ & - & {$[15]$} \\
\hline 6181-T4/6181-T4 & $1.7 / 1.7$ & $6.8 \mathrm{kN}$ & - & [7] \\
\hline 6022-T4/7075-T6 & $0.9 / 2.0$ & $4.19 \mathrm{kN}$ & - & {$[37]$} \\
\hline $\mathrm{AlMgSc} / \mathrm{AlMgSc}$ & $1.6 / 1.6$ & $9.34 \mathrm{kN}$ & - & [8] \\
\hline 7075-T6/7075-T6 & $1.6 / 0.8$ & $6.5-8.1 \mathrm{kN}$ & Plug-shear fracture & {$[38,39]$} \\
\hline 7050-T76/7050-T76 & $2.0 / 2.0$ & $11.3 \mathrm{kN}$ & - & [40] \\
\hline 6061-T6/7075-T6 & $3.0 / 3.0$ & $12.9 \mathrm{kN}$ & - & [41] \\
\hline AZ31/AZ31 & $2.0 / 2.0$ & $4.84 \mathrm{kN}$ & Non-circumferential pull-out & [12] \\
\hline 5754/AZ31 & $2.0 / 2.0$ & $3.75 \mathrm{kN}$ & Through-the-weld & [19] \\
\hline 5083/AZ31 & $1.8 / 1.8$ & $3.6 \mathrm{kN}$ & Through the IMC layer & {$[21]$} \\
\hline 5083/Cu-DHP & $2.0 / 2.0$ & $7.1 \mathrm{kN}$ & At the $\mathrm{Al} / \mathrm{Cu}$ interface & {$[23]$} \\
\hline 5754/Ti6Al4V & $2.0 / 2.5$ & $7.4 \mathrm{kN}$ & - & {$[33]$} \\
\hline 6181-T4/Ti6A14V & $1.5 / 1.5$ & $6449 \pm 554 \mathrm{~N}$ & At the interface & {$[28]$} \\
\hline PX-Al/galvanized steel & $1.0 / 1.2$ & $3.04 \mathrm{kN}$ & At $\mathrm{Al} /$ steel interface & {$[31]$} \\
\hline ST-Al/galvanized steel & $1.5 / 1.2$ & $4.5 \mathrm{kN}$ & At $\mathrm{Al} /$ steel interface & {$[31]$} \\
\hline 5754-O/AlSi-coated steel & $1.6 / 2.0$ & $4.44 \mathrm{kN}$ & At $\mathrm{Al} /$ steel interface & [29] \\
\hline 6022-T3/zinc-coated steel & $1.6 / 2.0$ & $6.95 \mathrm{kN}$ & At Al/steel interface & [29] \\
\hline $\mathrm{Al}-\mathrm{Mg}$ alloy/Zn-coated steel & $3.0 / 2.0$ & $7.8 \mathrm{kN}$ & - & {$[30]$} \\
\hline
\end{tabular}

hook profile at the joint interface and the reduction of IMC formation due to the process parameter optimization. The fatigue tests on $\mathrm{Mg} /$ zinc-coated steel joints showed that most fatigue fractures occurred at the sheet interface. Moreover, when the fracture propagation occurred through the parent $\mathrm{Mg}$ sheet, better fatigue properties were obtained due to the zinc brazing [45].

Two different fatigue failure modes were observed in FSpW Al/Ti specimens (Fig. 12 [33]). Under high cyclic loads, the failure occurred in the upper $\mathrm{Al}$ sheet with the crack initiation. Then, the crack propagation followed through the thickness toward the joint surface and, subsequently, along the specimen width direction. Under low cyclic loads, "through weld" failure was observed as the crack rapidly propagated along the interfacial surface until a critical point at which the remaining cross section could no longer sustain the shear overload and failed.

\section{Welding Tool}

The welding tool plays a critical role in $\mathrm{FSpW}$ process. However, the tool design has not been widely studied. The widely used welding tool in present researches includes a clamping ring, a sleeve and a pin. The tool geometry and the key dimensions of the pin and the sleeve are shown in Fig. 13. Thread is designed on the outer surface of sleeve and pin to enhance the material mixing and to avoid the material entering into the gap between the pin and the sleeve. A sleeve with a diameter of $9 \mathrm{~mm}$ is applied in most current researches [7, 35].

Using the typical tool, there are two kinds of processes: sleeve plunge (SP) and pin plunge (PP) [5]. The SP process was widely applied for performing FSpW since it could produce larger welds than that produced by PP process. High mechanical performance of spot joints was associated with large size of the stir zone [11]. Nasiri et al. [46] analyzed the tool failure in welding $2099 \mathrm{Al}-\mathrm{Li}$ alloy and found that high concentrations of $\mathrm{Li}$ between the pin and the sleeve, which led to the infiltration of lithium-rich liquid into the tool surfaces, resulted in the catastrophic wear of the tool.

In order to reduce the sensitivity of mechanical properties of the joint to welding parameters, Shen et al. [37] designed a novel tool sleeve with three grooves/notches, as shown in Fig. 14. The results indicated that improved metallurgical bonding, interlocking and intermixing were achieved, leading to a lamellar structure at the weld interface (Fig. 14c). 


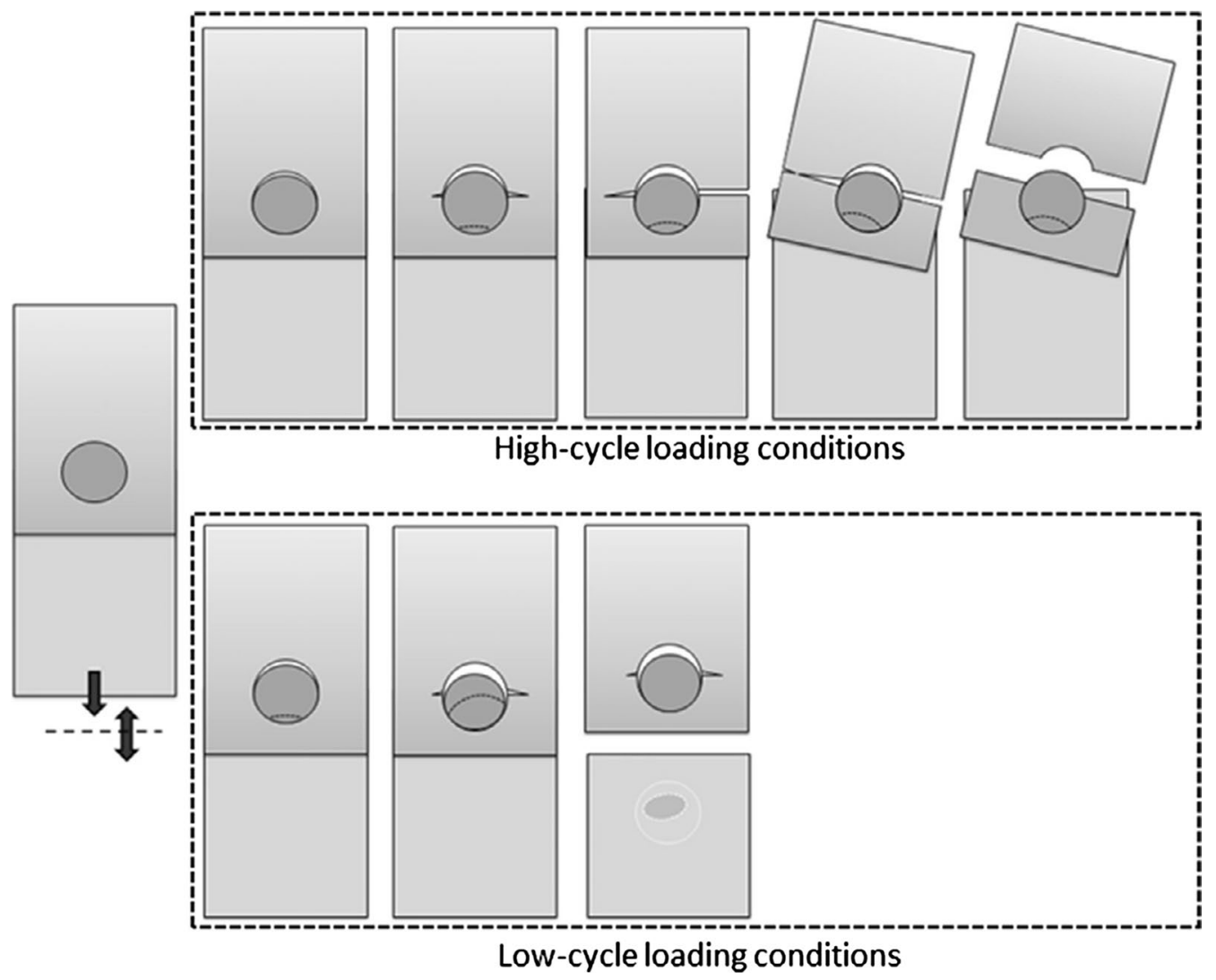

Fig. 12 Two different fatigue failure modes for AA5754/Ti6Al4V dissimilar joints under high and low cycle conditions [33]
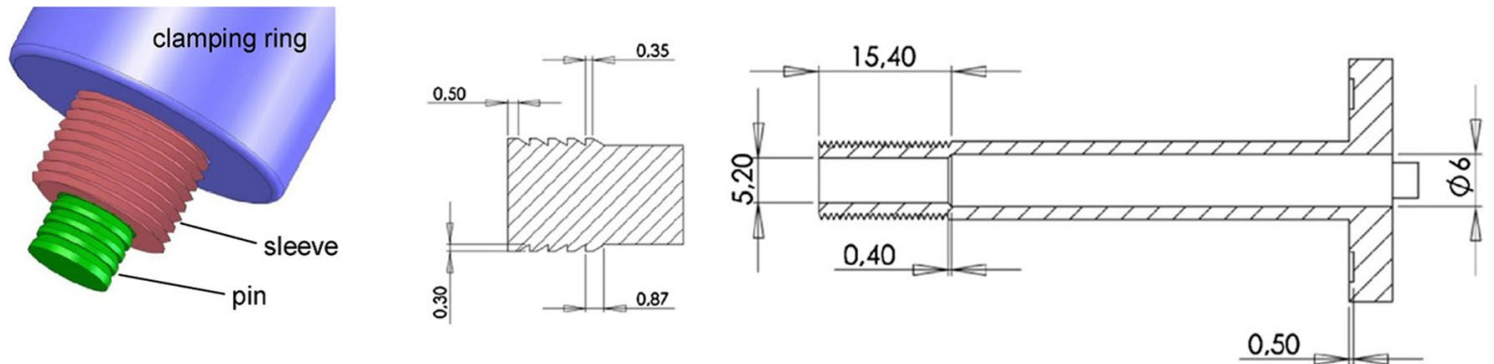

Fig. 13 Typical tool used to produce the friction spot welding welds [7, 35]

The welds fabricated by the modified tool exhibited high overlap shear strength with less sensitivity to welding parameters.

Tool failure analysis was conducted by Nasiri et al. [46] in the welding of $2099 \mathrm{Al}$ alloy with $1.69 \mathrm{wt} \% \mathrm{Li}$. The results showed that severe wear was observed at the interface between the tool pin, sleeve and clamp components (Fig. 15). The analysis of secondary ion-mass spectroscopy indicated that the wear regions contained phases with much higher concentrations of lithium than bulk 2099 Al material. The significant diffusion of the lithium into the steel tool surfaces was verified. The failure was attributed to local melting of the secondary phases originating from the 2099 $\mathrm{Al}$, which led to infiltration of lithium-rich liquid into the tool surfaces, resulting in liquid metal embrittlement and catastrophic wear.

\section{Application of FSpW}

Because of complicated procedures, long dwell time and inconsistency of welding strength, few applications about FSpW process were reported. Nevertheless, the improvement of the welding production efficiency, welding quality 


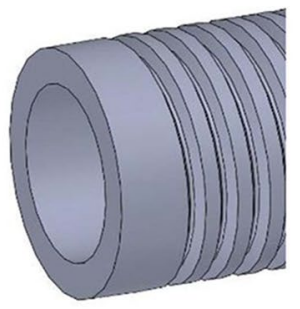

a
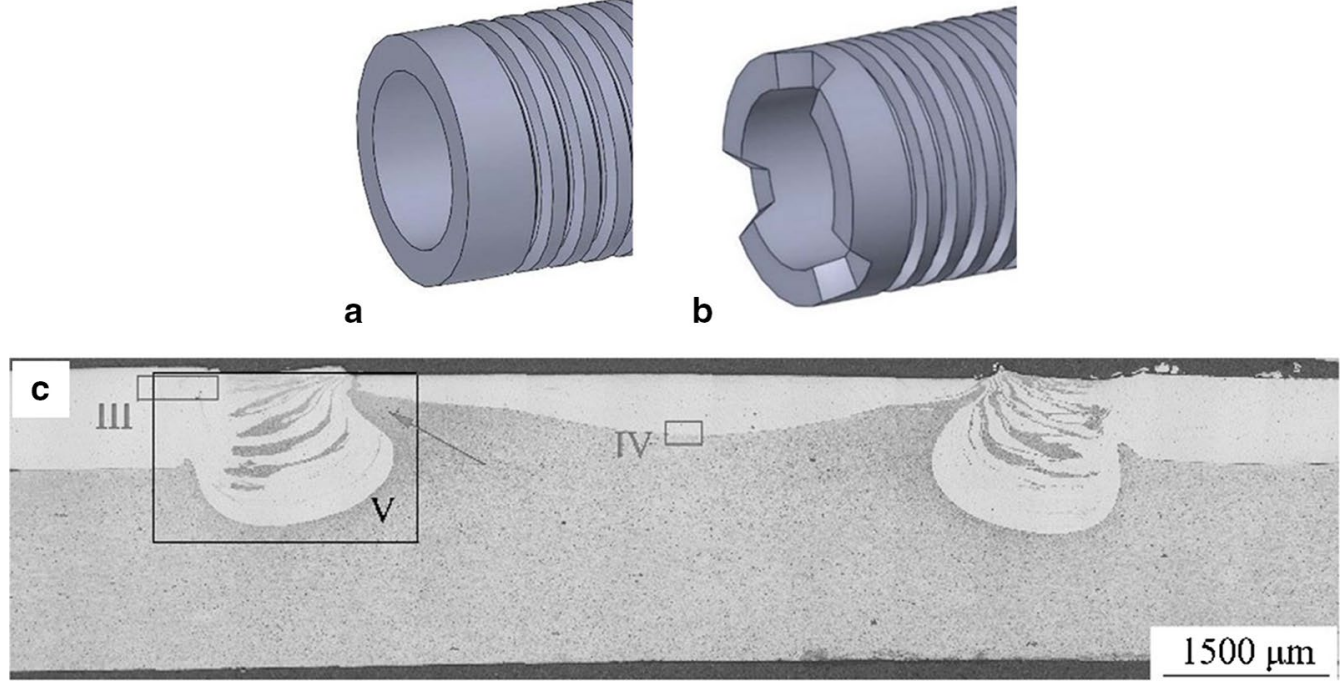

Fig. 14 Geometrical feature of the standard sleeve $\mathbf{a}$ and the modified sleeve $\mathbf{b}$; typical cross section of the weld fabricated by the modified tool c [37]

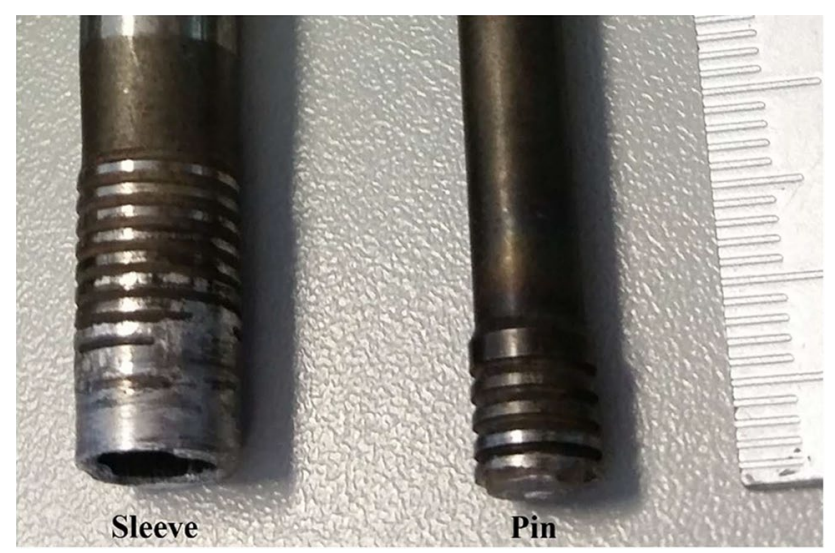

Fig. 15 Failed sleeve and pin tool in the welding of Al 2099-T83 alloy [46]

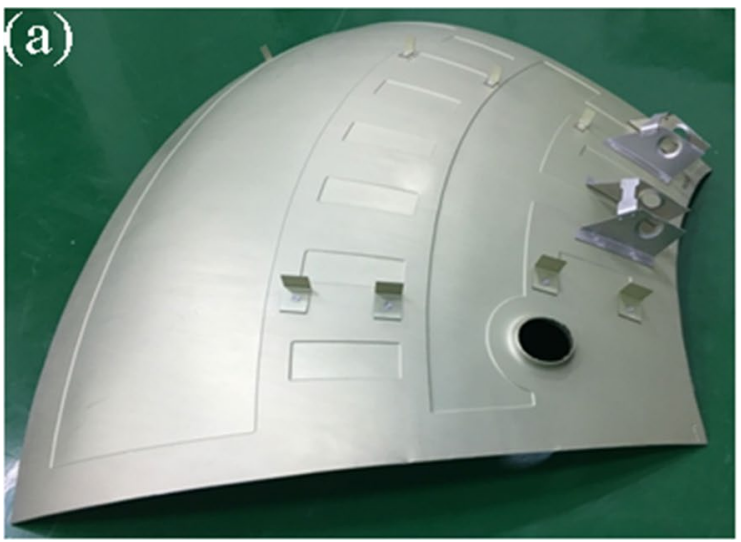

consistency of FSpW and the advantages of keyhole-free and high joint strength will provide a good application prospect. Some application attempts have been implemented in some industries, such as aerospace and rail transit. Figure 16a shows the FSpW welding sample of a rocket propellant tank part, with $\sim 10 \mathrm{kN}$ joint tensile shear strength achieved for $2 \mathrm{~A} 14 \mathrm{Al}$ base metal. For spacecraft structure, the spot welding structure has better weight reduction effect than riveting structure. Figure $16 \mathrm{~b}$ shows an application of FSpW process in a scaled sample of Al-Li alloy spacecraft cabin. Some advantages, such as good surface quality, low deformation, high stiffness and joining strength $(6.8 \mathrm{kN})$, were achieved.

The application research of FSpW process in fuselage (Fig. 17), the largest structure of an aircraft, was performed by Andrzej Kubit et al. [47]. 7075 Al-T6 alloy sheets with

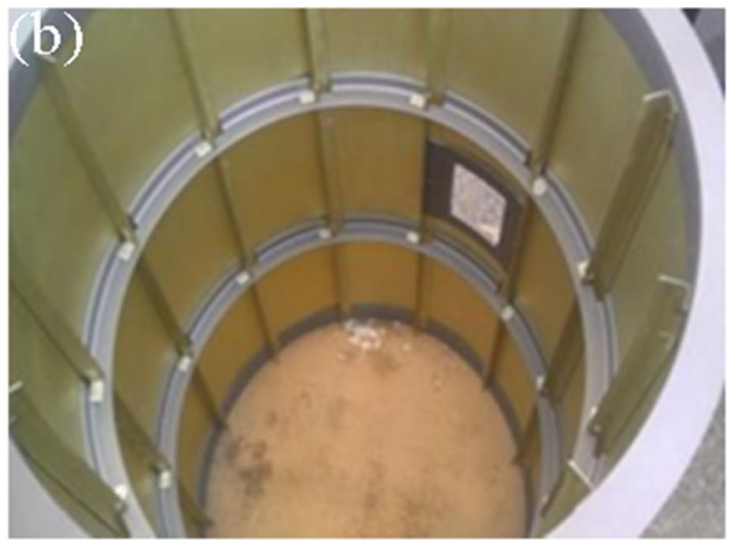

Fig. 16 Application samples of FSpW in aerospace for a rocket propellant tank parts; b Al-Li alloy spacecraft cabin 


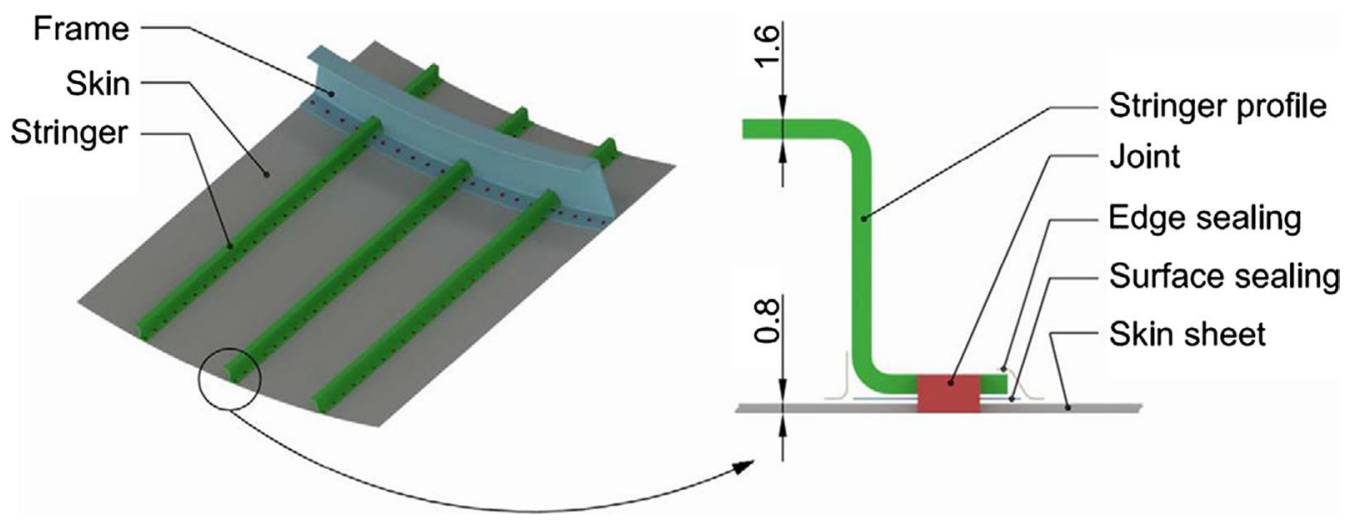

Fig. 17 FSpW connection of fuselage structure with sealant interlayer [47]

the addition of a sealant interlayer were connected by FSpW. The results showed that the polymer interlayer increased the protection of the weld against the corrosion environment. High tensile shear strength of FSpW joint with polymer interlayer was achieved, which is only $9 \%$ lower than the joint without the polymer interlayer. A novel methodology for squeezing the uncured interlayer out of the process area at the faying interface of the workpieces was performed [48]. Kubit et al. [42] also reported that C-SAM (C-mode scanning acoustic microscopy) can be used successfully for nondestructive testing of the FSpW welds of aircraft structure. Experimental and numerical stability analyses with compressive loading for aircraft skin panel fabricated by FSpW were conducted [49].

The FSpW process was also performed to refill the keyhole of FSW welds or remove the defects of welding and casting. The mechanical properties of the repaired location were evaluated by the tensile characteristics of the repairing FSW weld. It was found that a joint efficiency (the strength ratio of the joint and the base material) of $68 \%$ in 6061-T6 [24], 74\% (425 MPa) in 7075-T651 [3] and 78\% in 2198-T851 [4] was achieved, respectively. Lacki et al. [50] reported the application research on building structures via FSpW. A beam was made with the sheets of 6061 Al-T6 and titanium alloy which were connected by both FSpW and resistance spot welding (RSW) technology.

\section{Summary and Future Outlook}

Due to the nature of solid-state joining, $\mathrm{FSpW}$ is considered as a promising joining technology for lightweight materials with low melting point. And with the low joining temperature, the interface reaction in Al-based (or Mg-based) dissimilar joints, including AllMg, Al\Cu, AllTi and All Steel, could be better controlled with excellent mechanical properties.
However, the joint performance discreteness and the welding efficiency are the main challenges for the FSpW application. More effort should be put on the development of efficient welding tool and apparatus, aiming to improve the process stability and enhance the joining property. Although high mechanical properties had been achieved, further studies on material flow, defect behaviors, joint metallurgical reaction and their detailed effects on the joint performance should be performed. Furthermore, more attention should be paid on the joint fatigue properties, corrosion resistance and the mechanical properties, which are important for the industrial applications. The applications of the refill friction stir spot welding process in aerospace, aviation and automobile are promising.

Acknowledgements This work was financially supported by the National Natural Science Foundation of China (No. 51601117).

\section{References}

[1] C. Schilling, U.S. Patent 6,722,556, 20 Apr 2004

[2] M. Reimann, T. Gartner, U. Suhuddin, J. Göbel, J.F. dos Santos, J. Mater. Process. Technol. 237, 12 (2016)

[3] M. Reimann, J. Goebel, J.F. dos Santos, Mater. Des. 132, 283 (2017)

[4] M. Reimann, J. Goebel, T.M. Gartner, J.F. dos Santos, J. Mater. Process. Technol. 245, 157 (2017)

[5] T. Rosendo, B. Parra, M.A.D. Tier, A.A.M. da Silva, J.F. dos Santos, T.R. Strohaecker, N.G. Alcantara, Mater. Des. 32, 1094 (2011)

[6] R.C. Brzostek, U. Suhuddin, J.F. dos Santos, Fatigue Fract. Eng. Mater. Struct. 41, 1208 (2018)

[7] T. Rosendo, M. Tier, J. Mazzaferro, C. Mazzaferro, T.R. Strohaecker, J.F. Dos Santos, Fatigue Fract. Eng. Mater. Struct. 38, 1443 (2015)

[8] L.M. Santana, U.F.H. Suhuddin, M.H. Ölscher, T.R. Strohaecker, J.F. dos Santos, Int. J. Adv. Manuf. Technol. 92, 4213 (2017)

[9] S.B.M. Lage, L.C. Campanelli, A.P.B. Guerra, J.J. Shen, J.F. dos Santos, P.S.C.P. da Silva, C. Bolfarini, Int. J. Adv. Manuf. Technol. 100, 101 (2019) 
[10] J. Shen, S.B.M. Lage, U.F.H. Suhuddin, C. Bolfarini, J.F. dos Santos, Metall. Mater. Trans. A 49, 241 (2018)

[11] S.T. Amancio-Filho, A.P.C. Camillo, L. Bergmann, J.F. dos Santos, S.E. Kury, N.G.A. Machado, Mater. Trans. 52, 985 (2011)

[12] L.C. Campanelli, U.F.H. Suhuddin, A.Í.S. Antonialli, J.F. dos Santos, N.G. de Alcântara, C. Bolfarini, J. Mater. Process. Technol. 213, 515 (2013)

[13] U.F.H. Suhuddin, V. Fischer, J.F. dos Santos, Scr. Mater. 68, 87 (2013)

[14] C.C. de Castro, A.H. Plaine, G.P. Dias, N.G. de Alcantara, J.F. dos Santos, J. Mater. Process. Technol. 36, 330 (2018)

[15] J.Y. Cao, M. Wang, L. Kong, H.X. Zhao, P. Chai, Mater. Charact. 128, 54 (2017)

[16] Y. Uematsu, K. Tokaji, Y. Tozaki, T. Kurita, S. Murat, Int. J. Fatigue 30, 1956 (2008)

[17] Y. Zhao, C. Wang, J. Li, J. Tan, C. Dong, J. Mater. Technol. 34, 185 (2018)

[18] U. Suhuddin, V. Fischer, J. dos Santos, Mater. Sci. Forum 76, 731 (2013)

[19] U. Suhuddin, V. Fischer, F. Kroeff, J.F. Santos, Mater. Sci. Eng. A Struct. 590, 384 (2014)

[20] U. Suhuddin, V. Fischer, J.F. dos Santos, in Friction Stir Welding and Processing VII, ed. by R. Mishra, M.W. Mahoney, Y. Sato, Y. Hovanski, R. Verma (Springer, Cham, 2013), pp. 263-270

[21] Z. Dong, Q. Song, X. Ai, Z. Lv, J. Manuf. Process. 42, 106 (2019)

[22] J. Shen, U.F.H. Suhuddin, M.E.B. Cardillo, J.F. dos Santos, Appl. Phys. Lett. 104, 191901 (2014)

[23] M.E.B. Cardillo, J. Shen, N.G. de Alcântara, C.R.M. Afonso, J.F. dos Santos, Weld. World 63, 33 (2019)

[24] A.H. Plaine, U.F.H. Suhuddin, C.R.M. Afonso, N.G. Alcântara, J.F. dos Santos, Mater. Des. 93, 224 (2016)

[25] A.H. Plaine, U.F.H. Suhuddin, N.G. Alcântara, J.F. dos Santos, Int. J. Adv. Manuf. Technol. 92, 3703 (2017)

[26] G.S. Vacchi, A.H. Plaine, R. Silva, V.L. Sordi, U.F.H. Suhuddin, N.G. Alcântara, S.E. Kuri, C.A.D. Rovere, Mater. Des. 131, 127 (2017)

[27] P.S. Effertz, V. Infante, L. Quintino, U. Suhuddin, S. Hanke, J.F. dos Santos, Int. J. Fatigue 87, 381 (2016)

[28] A.H. Plaine, A.R. Gonzalez, U.F.H. Suhuddin, J.F. dos Santos, N.G. Alcântara, Mater. Des. 83, 36 (2015)

[29] Z. Shen, Y. Ding, J. Chen, B. Shalch Amirkhiz, J.Z. Wen, L. Fu, A.P. Gerlich, J. Mater. Sci. Technol. 6, 1027 (2019)
[30] U.F.H. Suhuddin, V. Fischer, A. Kostka, J.F. dos Santos, Sci. Technol. Weld. Join. 22, 658 (2017)

[31] H. Dong, S. Chen, Y. Song, X. Guo, X. Zhang, Z. Sun, Mater. Des. 94, 457 (2016)

[32] G. Pieta, J. dos Santos, T.R. Strohaecker, T. Clarke, Mater. Manuf. Process. 29, 934 (2014)

[33] A.H. Plaine, U.F.H. Suhuddin, N.G. Alcântara, J.F. dos Santos, Int. J. Fatigue 91, 149 (2016)

[34] G. Li, L. Zhou, L. Luo, X. Wu, N. Guo, J. Mater. Res. Technol. 8, 4115 (2019)

[35] M.D. Tier, T.S. Rosendo, J.F. dos Santos, N. Huber, J.A. Mazzaferro, C.P. Mazzaferro, T.R. Strohaecker, J. Mater. Process. Technol. 213, 997 (2013)

[36] Z. Xu, Z. Li, S. Ji, L. Zhang, J. Mater. Sci. Technol. 34, 878 (2018)

[37] Z. Shen, Y. Ding, O. Gopkalo, B. Diak, A.P. Gerlich, J. Mater. Process. Technol. 252, 751 (2018)

[38] A. Kubit, R. Kluz, T. Trzepiecińsk, D. Wydrzyński, W. Bochnowski, Arch. Civ. Mech. Eng. 18, 235 (2018)

[39] R. Kluz, A. Kubit, T. Trzepiecinski, K. Faes, Int. J. Adv. Manuf. Technol. 103, 3443 (2019)

[40] P.S. Effertz, L. Quintino, V. Infante, Int. J. Adv. Manuf. Technol. 91, 3683 (2017)

[41] Z. Liu, K. Yang, D. Yan, High Temp. Mater. Proc. 38, 69 (2019)

[42] A. Kubi, T. Trzepiecinski, K. Faes, M. Drabczyk, W. Bochnowski, M. Korzeniowski, Fatigue Fract. Eng. Mater. Struct. 42, 1308 (2019)

[43] R.C. Brzostek, U. Suhuddin, J.F. dos Santos, Fatigue Fract. Eng. Mater. Struct. 41, 1208 (2017)

[44] S. Venukumar, S. Muthukumaran, S.G. Yalagi, S.V. Kailas, Int. J. Fatigue 61, 93 (2014)

[45] Z. Shen, Y. Ding, J. Chen, A.P. Gerlich, Int. J. Fatigue 92, 78 (2016)

[46] A.M. Nasiri, Z. Shen, J.S.C. Hou, A.P. Gerlich, Eng. Fail. Anal 84, 25 (2018)

[47] A. Kubit, D. Wydrzynski, T. Trzepiecinski, Compos. Struct. 201, 389 (2018)

[48] E. Boldsaikhan, S. Fukada, M. Fujimoto, K. Kamimuki, H. Okadac, J. Manuf. Process. 42, 113 (2019)

[49] A. Kubit, T. Trzepiecinski, L. Swiech, K. Faes, J. Slota, Materials 12, 1785 (2019)

[50] P. Lacki, A. Derlatka, Compos. Struct. 159, 491 (2017) 